\title{
Assigning Search Tasks Designed to Elicit Exploratory Search Behaviors
}

\author{
Barbara M. Wildemuth \\ School of Information \& Library Science \\ University of North Carolina at Chapel Hill \\ Chapel Hill, NC, USA 27599-3360 \\ +01 919-962-8072 \\ wildemuth@unc.edu
}

\author{
Luanne Freund \\ School of Library, Archival \& Information Studies \\ University of British Columbia \\ Vancouver, BC, Canada V6T 1Z1 \\ +01604-822-0825 \\ luanne.freund@ubc.ca
}

\begin{abstract}
The goal of this paper is to provide guidance to researchers investigating exploratory search behaviors and exploratory search systems. It focuses on the design of search tasks assigned in such studies. Based on a review of past studies, a set of task characteristics associated with exploratory search tasks are identified: exploratory search tasks focus on learning and investigative search goals; they are general (rather than specific), open-ended, and often target multiple items/documents; they involve uncertainty and are motivated by ill-defined or ill-structured problems; they are dynamic and evolve over time; they are multi-faceted and may be procedurally complex; and they are often accompanied by other information or cognitive behaviors, such as sensemaking. Recommendations are provided for the design of search task descriptions that will elicit exploratory search behaviors.
\end{abstract}

\section{Author Keywords}

Exploratory search, Interactive information retrieval, Search tasks, Experiments

\section{ACM Classification Keywords}

H.3.3 Information search and retrieval: Search process

\section{General Terms}

Human Factors

\section{INTRODUCTION}

"Exploratory search is a type of information seeking and a type of sense-making focused on the gathering and use of information to foster intellectual development" [50, p.38]. In recent years, particularly since the 2006 ACM SIGIR Workshop on "Evaluating Exploratory Search Systems"

Permission to make digital or hard copies of part or all of this work for personal or classroom use is granted without fee provided that copies are not made or distributed for profit or commercial advantage and that copies bear this notice and the full citation on the first page. Copyrights for components of this work owned by others than ACM must be honored. Abstracting with credit is permitted. To copy otherwise, to republish, to post on servers or to redistribute to lists, requires prior specific permission and/or a fee.

HCIR 2012, October 04-05, 2012, Cambridge, MA

Copyright 2012 ACM 978-1-4503-1796-2/12/10 ...\$15.00.
[49], a number of experimental studies have examined exploratory search behaviors. Unfortunately, not all the researchers have used the same definition of exploratory search and none, as far as we have discovered, have re-used the search tasks assigned by any of their colleagues. Thus, results are not easily comparable across studies.

The goal of this paper is to take a step toward remedying this situation. Interactive information retrieval (IR) researchers need to be able to design search tasks that can be assigned to experimental subjects to elicit exploratory search behaviors and outcomes. As Kules and Capra [27] have pointed out, "designing tasks for studies of exploratory search can be especially difficult due to the goal of inducing an exploratory (rather than directed) style search, wherein searchers will individually interpret the tasks, their relevance, and the results - while maintaining some level of experimental control" [27, p.116]. If we can identify and clearly specify the attributes of exploratory search tasks, then we can design tasks that will more reliably prompt this style of searching, leading to better understanding of how people conduct exploratory searches and what types of interaction and functional support are needed to maximize their effectiveness.

This paper will first review some foundational concepts related to search tasks in general. It will then discuss attributes of exploratory search tasks that have been identified and used to design the tasks assigned in interactive IR research. This review of exploratory search task attributes, and the examples provided, are drawn from a systematic compilation of empirical studies and conceptual/theoretical papers identified for a larger project that is examining the assignment of a variety of types of search tasks [http://ils.unc.edu/searchtasks/]. An online database of these papers will be made available to other scholars in the near future; it currently holds approximately 700 references, and more studies are being added as they appear. Any tasks assigned in any of the studies are being recorded and described in the database. The database was searched for any studies in which the assigned search task 
definitions included the terms: exploratory, learn*, investigat*, or open. Of the 84 papers identified in this way, 51 (including both empirical and conceptual papers) were found to be pertinent to exploratory search tasks. Thus, this paper is grounded in the current practices and thinking of interactive IR researchers. Each author's discussion of exploratory search tasks was inductively analyzed for the key attributes used to describe, specify, or design exploratory search tasks; thus, the data analysis approach used here is similar to that applied in other qualitative research studies. The paper concludes with recommendations for developing exploratory search tasks, augmenting those already offered by Kules and Capra [28].

\section{FOUNDATIONAL CONCEPTS}

Any discussion of search tasks must be placed within the context of the foundational work of Byström and Hansen [9]. They characterized tasks that are important to interactive IR researchers as occurring at three levels: informationintensive work tasks, information seeking tasks, and information search tasks. Here, we refer to these three levels as work tasks, information seeking tasks, and search tasks; exploratory search tasks are regarded as one type of search task.

Work tasks are "an activity people perform to fulfill their responsibility for their work" [30, p.275], and have often been studied within the context of a work setting. However, a number of information behavior (IB) scholars have also extended this concept to tasks in everyday life [43]. The information-intensive work tasks that are of interest to both interactive IR and IB researchers are "characterized by the fact that they involve inherently and/or explicitly information-related activities to a considerable degree" [9, p.1050]. These work tasks may inspire the simulated work task scenarios recommended by Borlund and Schneider [8], but can be distinguished from the search tasks of interest here.

Information seeking is an integral part of accomplishing an information-intensive work task. The task performer often needs additional information, and so will seek it from any of a variety of sources, both documentary and interpersonal/social. Li [30] defines information seeking tasks as "the activities that users engage in for gathering information for their work or life" [30, p.275]. A number of information seeking episodes may be involved in the accomplishment of a single work task. Similarly, an information seeking task may be composed of a number of search tasks. Search tasks are also called information retrieval tasks, and are associated with searching an information retrieval system (rather than another type of source).

This three-level characterization of tasks was generated from and is usually used to describe the tasks being accomplished in real-world settings. However, there are two faces to this coin. Byström and Hansen [9] distinguish between task descriptions and task processes. Task descriptions define a particular item of work, specifying the task requirements and goals; task processes are the behaviors manifested in the performance of a task. Gill and
Hicks [17] follow a similar line of reasoning by distinguishing tasks "as a set of required behaviors" from tasks "as a set of resultant behaviors" [17, p.3]. This distinction has shown up most clearly in the empirical work of Toms et al. [45], as they investigated the effects of task descriptions on search behaviors (i.e., task processes).

This paper is concerned with search tasks - the lowest level of the task hierarchy. In addition, its purpose is to provide an analysis that will assist researchers in designing improved search task descriptions - the requirements and goal specifications that might be provided to a subject in an interactive IR experiment. The discussion below is based primarily on empirical studies in which search tasks were assigned to study participants and to conceptual papers reviewing concepts related to search tasks. The particular focus is on exploratory search tasks (i.e., search tasks that are intended to elicit exploratory search behaviors and outcomes).

\section{ATTRIBUTES OF EXPLORATORY SEARCH TASKS}

General definitions of exploration refer to the investigation and examination of something in order to learn about it and make discoveries. The spatial metaphor implicit in the concept of exploration reflects a purposeful and thorough, although undirected, movement through the various components of the physical or conceptual object of interest.

Although very few interactive IR researchers have been willing to venture a definition of exploratory search tasks or behaviors, the operational concept seems to be closely aligned with that of exploration more generally. Most often, exploratory search tasks are discussed in terms of their key attributes. Each researcher has emphasized one or more of these task attributes, which include their association with learning and investigation, aspects of the search goal and the problem being addressed by the search, the dynamic nature of exploratory search tasks, the time frame in which they're accomplished, their multi-faceted nature and procedural complexity, and the other information or cognitive behaviors associated with their completion. Each of these attributes will be discussed in turn.

\section{Exploratory search tasks are associated with the goals of learning and/or investigation}

In Marchionini's seminal [35] paper on exploratory search, he depicted exploratory search processes as involving two major types of search activities: learning and investigation. White and Roth [50], in their recent review of exploratory search, also preserved this perspective, expanding it slightly to argue that learning "is not only about knowledge acquisition, but rather the development of higher-level intellectual capabilities within a particular subject area" [50, p.13]. Similarly, Vakkari [46] maintained the link to both learning and investigative search goals. He suggested that investigative search is invoked "when actors are exploring possible conceptualizations of their topic" [46, p.3], and that learning is illustrated by the increase in the exhaustivity and specificity of the searcher's mental model of the topic as the search progresses. 
Most of the empirical studies since 2006 have incorporated one or both of these ideas. Kim's [25] search tasks were intended "to foster learning or investigation" [25, p.683]. Wolfram and Dimitroff [51] assigned investigative search tasks in their early study, though they did not refer to them as exploratory search tasks. Several researchers indicated that the searchers' goal is to learn or gain knowledge about the search topic $[4,13,40]$. Often, the exploratory search tasks that are focused on the goal of learning are situated within an academic context. Here is an example:

You've been given an assignment in class on racial profiling, and are expected to write a paper on it. You decide to begin by trying to understand what racial profiling is, and explore and examine the issues, organisations and laws concerning it. [13, p.57]

Others [2, 14, 28] augment the discussion of learning by indicating that comparison, as a cognitive behavior, is part of the search process in exploratory search. For example, Alhenshiri and colleagues [2] posed an exploratory search task asking for a comparison of Canadian universities that might be considered for a graduate degree in business.

Jansen et al. [22] and Wu et al. [53] expanded this idea even further, using a formal taxonomy of cognitive learning [3] to develop search tasks; the higher levels of this taxonomy seem likely to elicit exploratory search behaviors, though they were used by both these research teams as indicators of increasing cognitive complexity. The highest level of the taxonomy, Creating, is described as "Putting elements together to form a coherent or functional whole; reorganizing elements into a new pattern or structure through generating, planning, or producing." An example of a search task at this level is:

Your great granny's doctor has told her that getting more exercise will increase her fitness and help her avoid injuries. Your great granny does not use the Internet and has asked you to create an exercise program for her. She is 90-years old. Put together two thirty-minute low-impact exercise programs that she could alternate between during the week. $[53, \mathrm{p} .4]$

While there is a great deal of variation - both conceptual and practical - in researchers' approaches to this attribute in the design of search tasks, it is clear that learning and investigation are widely accepted goals for exploratory search tasks.

\section{Exploratory search tasks are general, rather than specific}

Because many researchers are trying to compare exploratory search tasks with known-item tasks or fact-finding tasks, they depict their exploratory search tasks as general in nature. "General" refers to conceptually broad search topics as well as task descriptions that are vague and under-specified (i.e., ill-defined). The effect in either case is that the searcher has considerable latitude in directing the search. As Kules and Capra [28] suggest, exploratory search tasks should "provide a low level of specificity about: the information necessary for their search, how to find the required information, [and] how to recognize the required information" [28, p.19]. Diriye, Blandford, and Tombros $[12,13]$ focus their search tasks on general topics; Niu and Winter [37] focus on "non-specific information needs" [37, p.796]; Schacter, Chung, and Dorr [44, p.844] assign search tasks with "vague goals" with "no clear directions for when to stop solving the problem"; and Kim [24] contrasts specific and general questions to develop factual, interpretive, and exploratory search tasks. Here is an example of an exploratory search task assigned in that study:

You have recently moved to Boston and you are interested in buying a home. You have heard that most homes built before 1978 have some lead paint, but that their paint status is often reported as "unknown." You think you should learn about lead paint and housing. The Web seems like a good place to locate this information. [25, p. 684]

Some authors have described this attribute as the abstractness of the search goal. MacMullin and Taylor [32] were the first to take this perspective, arguing that goals associated with information problems ranged from specific to amorphous. $\mathrm{Li}$ [30] repeated this view in a recent study relating the attributes of work tasks and search tasks. Aula and Russell [5] stated this view most clearly, indicating that "a search is deemed exploratory when the searcher has a very abstract search goal" [5, p.24].

\section{Exploratory search tasks are open-ended}

Much like the general-specific dichotomy, discussions of open-ended versus closed questions have been part of our literature since the early days of interactive IR research. For example, one of Marchionini's early studies [36] included open-ended general information tasks and open-ended questions, described as questions "for which there was no specific answer" [36, p.44]. It could easily be argued that these search tasks led to his later work on exploratory search tasks. An example is: "How are power companies coping with the economic problems of global warming?" [36, p.69].

While most researchers today impose more criteria within the definition of exploratory search tasks than that they be open-ended, it is also true that most would agree that all exploratory searches are open-ended. Li and Belkin [31] make this connection clear, when they note that the open-ended tasks used by Marchionini in his early studies correspond to what they are calling "subject search tasks", but that most scholars now call these "exploratory" search tasks. Some of the other scholars that have described exploratory search task descriptions as open-ended include Diriye, Wilson, Blandford, and Tombros [14], Kim [25], Ramdeem and Hemminger [41], White and Iivonen [48], and White and Roth [50]. 


\section{The target of an exploratory search is multiple items}

The concept of an open-ended search task usually implies that the target of the search is multiple items/documents. Marchionini [35] is explicit in his observation that learning-oriented searches return sets of documents; Schacter, Chung, and Dorr [44] note that one of the characteristics of an ill-defined problem is that there are "many possible solutions" [44, p.844]; and Vakkari [46] notes that exploratory searches "have no identifiable 'correct' solution" [p.1].

Others have taken an even stronger position in applying this attribute by distinguishing exploratory search tasks from other types of search tasks based on the number of items intended to be retrieved. Kules and Capra [28] used this attribute to distinguish exploratory tasks from known-item tasks; and both Madden et al. [33] and Marchionini [34] used this attribute to identify open-ended tasks.

Because the target of an exploratory search task is a set of items, some researchers have included a target number of items in the task description itself. Wolfram and Dimitroff [52] had their subjects complete three subject searches each, "one in which there was a small number of relevant records in the database (Qsmall), one with a mid-sized number of relevant records (Qmedium) and one with a large number of relevant records (Qlarge), as determined by the investigators" [52, p.672]. Xie and Cool [54], Niu and Winter [37], Schacter, Chung, and Dorr [44], and Ramdeen and Hemminger [41] each asked their subjects to retrieve a particular number of items for each task, as illustrated by these examples:

This semester you are taking an American History class. For an assignment you are asked to find three documents that deal with the economic aspects of the Civil War in North Carolina. [41, p.715, emphasis added]

What should be done to reduce crime in California? Find at least three pieces of information on the Internet that will help you develop a plan to reduce crime in California. You need to find information to make a plan that other people will agree is a good, usable, and practical way to reduce crime in California. Find three pieces of information on the Internet that will support your plan. [44, p.844, emphasis added]

While it is relatively simple to manipulate this variable, it is not clear that requiring searchers to find a set number of items prompts naturalistic exploratory search behavior or outcomes. More research is needed to investigate the potential effects of this practice.

\section{Exploratory search tasks involve uncertainty}

A number of researchers have suggested that some level of uncertainty is associated with exploratory search tasks. Some [2, 14, 28, 29] have positioned the uncertainty as a characteristic of the information need underlying the task; some $[15,38]$ as a characteristic of the topic; some [48] as a characteristic of the sources that might resolve the information need; and some $[37,50]$ as a characteristic of the search outcomes. It is clearly a challenge to build uncertainty into an exploratory search task description, but one approach is exemplified here:

Imagine you are taking a class titled "Great Britain and its Colonies in the Twentieth Century". For this class you need to write a research paper on some aspect of the relationship between Great Britain and its Colonies in the Twentieth Century but you have yet to decide on one. Use the [library] catalog to find two possible topics for your paper. Then use the catalog to find three books for each topic so that you might make a decision as to which topic to write about. [27, p.138]

In this example, there is explicit uncertainty related to the possible topic for a paper. Working through this uncertainty becomes an implicit part of the assigned task.

\section{Information problems that elicit exploratory search} behaviors are ill-structured

Following the lead of MacMullin and Taylor [32], who observed that information problems vary in amount of structure (from well-structured to ill-structured), most of those studying exploratory search have positioned the lack of structure as a characteristic of the underlying question, problem, or information need. These researchers include Bilal [6], Capra and his colleagues [10], Kim [25], Schacter, Chung, and Dorr [44], Vakkari [44], and White and Roth [50]. MacMullin and Taylor's description indicated that ill-structured information problems are those that "cannot be resolved through strictly analytical means" [32, p.103]. It is not completely clear whether or not the other researchers have agreed with this definition, since they vary in whether they provide a definition or explanation and, if they do, how it is stated. For example, Kim [25] describes a "vaguely structured information need" as one for which the information required to address it cannot be determined in advance, while Vibert et al. [47] took a more inductive approach by designing moderately ill-structured search tasks based on "real examples of online bibliographic searches" analyzed in an earlier study [47, p.1427]. These tasks specified that the subject should search for a particular number of articles on a topic, but no other structure was provided:

Find two articles published in 2004 dealing with the links between neurogenesis and Alzheimer's disease. [47, p.1443]

Almost all of the discussions of lack of structure have focused on the lack of structure in the information need/problem or the task. However, a few researchers have also discussed the lack of definition or structure in the searcher's current knowledge. These scholars [e.g., 19, 37, 50] take the view that exploratory search behaviors occur when the searcher's knowledge of the problem domain or terminology is deficient. This issue will also be raised in the next section on the dynamic nature of exploratory searching. 


\section{Exploratory search processes are dynamic}

As White and Roth [50] point out, "the problem context is... highly dynamic in exploratory search scenarios" [50, p.16]. The idea here is that the information need and/or problem definition evolves and changes as the search progresses [10, 15, 47]. These changes may be due to external events associated with the information problem, the searcher's changing understanding of the topic as results are retrieved, or internal changes in the searcher's motivations or interests [28, 29]. The following search task, with its rich context, illustrates how such evolution can take place:

Imagine that you are a reporter for a national newspaper. Due to some recent events, your editor has just asked you to generate a list of ideas for a series of articles on [the aging workforce]. There's a meeting in an hour, so she does not need a lot of detail, but she wants a diverse list of 8-10 (or more) ideas for discussion. They should cover many different aspects of the topic, to appeal to a broad range of readers. Unusual or provocative ideas are good. You have about 10 minutes to conduct a short web search to find out what information is available and generate the ideas. Your results will be judged (by your imaginary editor) on the quality and diversity of ideas. For example, "public health impact" would be an okay idea and "obesity as a public health impact of urban sprawl" would be even better, because it is a bit more specific. [29, p.482]

Evolution of the search topic or the search itself may be "a moment-by-moment activity", as suggested by Janiszewski [21, p.291]. However, it may also take longer. Marchionini [35] notes that both learning-oriented and investigative searches require multiple iterations, and $\mathrm{He}$ et al. [18] suggest that such searches are likely to occur over multiple search sessions. The theme of the passage of time has also been picked up and discussed in its own right.

\section{Exploratory search processes occur over time}

In her recent examination of the facets of search tasks, Li [30] identified time (length) as a generic facet of an information search task; it may be short term or long term. As we will see, most researchers would argue that exploratory search processes tend to be long term. White and Roth [50] describe exploratory search tasks as requiring "multiple query iterations and potentially multiple search sessions... [lasting] for days, weeks, or months" [50, p.21]. $\mathrm{Qu}$ and Furnas [40] indicate that multiple searches are necessary to complete an exploratory search task, and Capra et al. [10] agree that an exploratory search can involve multiple search sessions. In a naturalistic study of academic research tasks, Du and Evans [15] characterized such tasks as successive searches occurring over time.

The challenge posed by this attribute is that experimental subjects are unlikely to be willing to conduct successive searches over multiple search sessions for an assigned search task. Madden, Eaglestone, Ford, and Whittle [33] were successful in imposing short-term (i.e., single session) multi-stage searches. These searches required the participant to find more than one piece of information. For example, one of the multi-state tasks was: "Find the postcode of the tallest British building outside of London." A similar approach could be extended to other studies of exploratory search.

\section{Exploratory search tasks are multi-faceted}

Describing a search task description as multi-faceted means that it "includes multiple aspects or a number of concepts" [26, p.683]. Most often, the search task description incorporates multiple subtasks $[14,15,40,50]$. For example, Wolfram and Dimitroff's [52] investigative tasks each included two facets: "Find documents about library planning activities in public libraries." [52, p.678]. Schacter, Chung and Dorr [44] connect this attribute to the ill-defined nature of exploratory search problems, noting that such problems have "a large number of open constraints requiring resolution" [44, p.844].

Toms and her colleagues [45] analyzed this attribute in more detail. They contrasted two different multi-faceted task structures. The first is a parallel structure, in which the different facets are "on the same level in a conceptual hierarchy" [45, p.362]. An example of an information gathering task description that uses a parallel structure is:

Friends are planning to build a new house and have heard that using solar energy panels for heating can save a lot of money. Since they do not know anything about home heating and the issues involved, they have asked for your help. You are uncertain as well, and do some research to identify some issues that need to be considered in deciding between more conventional methods of home heating and solar panels. [45, p.363]

The second type of structure is a hierarchical structure, characterized by "a single concept for which multiple attributes or characteristics are sought" [45, p.362]. An example of a decision making task description that uses a hierarchical structure is:

Your friends who have an interest in art have been debating the French Impressionism exhibit at a local art gallery. One claims that Renoir is the best impressionist ever, while the other argues for another. You decide to do some research first so you can enter the debate. You consider Degas, Monet and Renoir to construct an argument for the one that best represents the spirit of the impressionist movement. Who will you choose and why? [45, p.363]

The number of facets in an exploratory search task description can be experimentally manipulated, if we find evidence that the number of facets affects search outcomes or search processes. 


\section{Exploratory search tasks are "not too easy"}

It may be noticeable, by now, that there has been no discussion of the complexity of exploratory search tasks. Most researchers seem to have taken the position that complexity or difficulty of the search task is independent of the exploratory nature of the task, thus making complexity a distinct variable that can be manipulated in an experimental study. However, there are a few hints that complexity is sometimes considered salient to the definition of an exploratory search task.

In Kules and Capra's recent guidelines for developing exploratory search task descriptions, they did not include complexity among the key attributes of exploratory search tasks. However, they did note that, for their own study, they wanted to design search tasks that were "not too easy to qualify for use in an exploratory search" [28, p.19]. Diriye, Blandford, and Tombros [12] also noted that their task type definitions include considerations of the tasks' complexity and difficulty, and Niu and Winter [37] argued that "exploratory search tasks... are often motivated by complex problems" [37, p.795].

Even more directly, Diriye, Wilson, Blandford, and Tombros [14] identified procedural complexity as a key attribute of exploratory searches. Procedural complexity is different from conceptual complexity and defined as "the number of subtasks and steps involved in a search task" [p.2]. He et al. [18] and Niu and Winter [37] also noted that exploratory search task processes often involve multiple subtasks or "iterative query steps" [37, p.796].

Given these varying views of the inherent complexity or difficulty of exploratory search tasks, there is value in the recommendations of Kules and Capra [28], that exploratory search tasks should be designed to be "not too easy", leaving open the possibility of designing tasks at varying levels of complexity.

Exploratory search processes are accompanied by other information/cognitive behaviors

Qu and Furnas [39, 40] have identified a number of other information or cognitive behaviors that frequently accompany exploratory search behaviors. These include sensemaking; organizing and analyzing search results; and decision making. Each of these has been discussed and/or investigated by subsequent researchers.

Sensemaking is the behavior that has been associated with exploratory search most frequently. Qu and Furnas [39, 40] adapted the ideas of Dervin [11] and Russell et al. [42], defining sensemaking in this context as "a process of searching for a representation and encoding data in the representation to answer task-specific questions" [39, p.269]. Vakkari [46] also noted the relationship between exploratory searching and sensemaking, observing that the solution to a problem is created, not found. "Actors search information for obtaining concepts and their relations in order to understand, structure and represent their task more validly for proceeding in its performance" [46, p.1]. Both White and Roth [50] and Diriye, Wilson, Blandford, and
Tombros [14] agree, claiming that exploratory searches inherently involve sensemaking.

Organizing and analyzing search results may be seen as activities that are carried out during the process of sensemaking, and so they are. However, they are also discussed separately, in connection with exploratory search processes. Marchionini's [35] model of exploratory search includes interpretation, comparison, and aggregation/ integration as activities associated with learning-oriented searches, and analysis, synthesis, evaluation, and transformation as activities associated with investigative searches. Diriye, Blandford, and Tombros [13] expected the collation of information and the analysis of results as search activities. Because exploratory searches are conducted for the purposes of learning and investigation, observations of these accompanying behaviors of organization and analysis are not surprising.

Some researchers also discuss decision making processes in association with exploratory search. They are considering decision making from a higher level than the routine relevance decisions made while conducting any type of search; rather, they are focused on decision making as a motivation for the search task or as a component of the work task that instigated the search behaviors. For example, White and Roth [50] claim that "exploratory searches are generally conducted to help people make more informed decisions" [50, p.22]. To unambiguously tie these two types of behaviors together, Kang, Kannampallil, $\mathrm{He}$, and Fu [23] made a purchasing decision an explicit part of their exploratory search task descriptions. Their study participants were asked to use an experimental bookstore website to identify books they would recommend for a library in each of eight different settings (e.g., a retirement community or a software company). This activity goes beyond Marchionini's [35] original and widely-used focus on learning and investigative searches; those investigating exploratory search will need to consider further whether the traditional view of the motivations for exploratory searches should be expanded to include decision making or other types of work tasks.

\section{LESSONS LEARNED}

This systematic review of the literature updates and augments two important prior reviews. White and Roth [50] synthesized our current understanding of exploratory search processes, and then focused their discussion on exploratory search systems and their evaluation. It is a necessary primer for anyone interested in studying exploratory search processes or designing search systems that will support those processes. In their review, Diriye, Wilson, Blandford, and Tombros [14] identified the search objective, the search activities, conceptual complexity, and procedural complexity as key attributes of exploratory search processes, and focused their recommendations on the potential contributions that the field of human-computer interaction could make to designing retrieval systems that will support exploratory search. 
The current review focuses more specifically on key attributes of exploratory search tasks so that interactive IR researchers can develop valid task descriptions - the brief statements or questions that guide the searching processes of a subject in an experiment. The goal of this review is to move the field toward a standard vocabulary for defining exploratory search and its attributes and developing and applying exploratory search tasks. The attributes identified through this review are summarized in Table 1, grouped according to two aspects of search tasks. Cognitive attributes include those that involve the reasoning associated with developing and conducting an exploratory search. Behavioral attributes focus on the behaviors that can be observed while an exploratory search is conducted.

\begin{tabular}{|l|l|}
\hline Categories & Attributes \\
\hline Cognitive & $\begin{array}{l}\text { Learning and investigation as goals } \\
\text { General problem, not specific } \\
\text { Uncertainty is involved } \\
\text { Ill-structured problem } \\
\text { Dynamic, evolution during search } \\
\text { Multi-faceted } \\
\text { "Not too easy" } \\
\text { Accompanied by sensemaking, decision } \\
\text { making or other cognition }\end{array}$ \\
\hline Behavioral & $\begin{array}{l}\text { Open-ended problem } \\
\text { Target is multiple items } \\
\text { Occurs over time }\end{array}$ \\
\hline
\end{tabular}

Table 1: Summary of exploratory search task attributes

The design of exploratory search tasks, then, begins with a focus on work tasks with the goals of learning and investigation (and, possibly, decision making). It requires careful selection of general and open-ended topics that are ill-structured, involve some uncertainty and the evolution of the search strategy, are multi-faceted, and are somewhat difficult to search for. Furthermore, the task scenario will motivate the searcher to spend a considerable amount of time searching for and interacting with multiple documents.

\section{RECOMMENDATIONS FOR EXPLORATORY SEARCH TASK DESIGN}

As noted by Kules and Capra, the aim in designing search task descriptions is to make them as authentic as possible [9]. Tasks that are authentic will induce more naturalistic behavior, which will increase the external validity of the study findings. One approach is to make use of simulated work task situations as a framework for designing search task descriptions, as proposed by Borlund [7]. Note that, in this process, a work task is simulated in order to motivate a search task; thus, simulated work task situations span the different levels of the task hierarchy, explicitly using the context of the work task to influence the search task processes. Borlund and Schneider [8] have recently reconsidered the usefulness of simulated work task situations as task descriptions in interactive IR research. They point out that, although simulated work task situations have been used in many studies (they review 85 of them), they have not been formally validated. Nevertheless, there are at least a couple of reasons why simulated work task situations are particularly appropriate as search task descriptions in studies of exploratory search. First, given the inherently ambiguous nature of exploratory search tasks, the use of simulated work task situations can help to clarify the information problem for the study subject. While too much clarification must be avoided (because it will cause the search task to lose a key attribute of exploratory search), the subject can still benefit from knowing something about "the source of the information need, the environment of the situation, the problem which has to be solved, and... the objective of the search" [8, p.156]. Second, the contextual information provided by a simulated work task situation will help to motivate the study subject to persevere in a multi-faceted, dynamic exploratory search that can take a good bit of time.

Byström and Hansen [9] propose a well-structured approach to the development of simulated work task descriptions that can be applied in experimental settings. They suggest that the researcher begin by eliciting real-life situations and task cases that are relevant to the study being designed. This elicitation process has occurred in past studies, using at least two different methods. One method is to interview and/or observe people completing their work tasks, to identify the salient aspects of the context and situation. A second method is to analyze transaction logs of IR systems; from the expressions of queries recorded in the logs, realistic (though fictional) work task scenarios could be generated. With some real-life examples in hand, the researcher is ready to start developing the simulated work task scenario. In the simulated scenario, both the context of the work task and the specific situation need to be described. Finally, a suggestion of what to look for can be provided; this is called the "indicative request" by Borlund [7]. Using this framework, studies of exploratory search can incorporate a variety of search task descriptions and can begin to investigate the aspects of exploratory search processes that have an effect on search outcomes.

The establishment and clear documentation of the purpose for the search task and the attributes of exploratory search tasks can also lead the researcher to more appropriate measures of evaluation [37, 43]. Given the attributes of exploratory search tasks, White, Muresan and Marchionini claim that measurement of "interaction behaviors, cognitive load, and learning" is appropriate [49, p.2]. While many of the studies reviewed here do assess interaction behaviors [e.g., 2, 10, 13, 24], fewer assess cognitive load [10, 13] or learning $[16,22,53]$. The assessment of learning is rare in IR research, but there are precedents. Some studies have used sets of questions or problems related to the search topic to assess learning $[19,51]$; others have used written summaries or concept maps [16]. Looking to cognate fields may also be useful. In particular, hypertext research has a long tradition of examining the cognitive effects of interaction with texts, including comprehension and learning [e.g., 1], and much of this work is based on well-developed theoretical models, such as Kintsch's model of comprehension [26]. 
In summary, it is recommended that exploratory search experiments incorporate simulated work task situations as stimuli for eliciting exploratory search behaviors. These simulated work task situations should have the following attributes to represent our current definition of exploratory search:

- The work tasks that are the focus of the simulations should be oriented toward learning and investigation tasks. They may include everyday life information problems; a work task does not have to be completed within a "work" setting.

- The context and situation for the work task should be clearly specified; the topic or indicative request is an opportunity for introducing some ambiguity. Topic assignments that are open-ended and/or target multiple items as results are more likely to elicit exploratory search behaviors. A balance needs to be struck between the standardization required for an experiment (in which each subject is performing the same assigned task) and the inherent flexibility of exploratory search.

- Multiple facets should be included in the simulated work task situations and the search topics. Introducing multi-faceted search tasks will serve the dual purpose of making the simulated work task situations more realistic and ensuring that they are not too simple to evoke exploratory search behaviors.

- Possibilities for eliciting dynamic multi-stage searches should be considered. The most obvious approach would be to write the simulated work task situations as involving multiple stages; however, this approach will not capture the types of changes in the search processes that might be invoked by changes in the searcher's understanding of the problem. Longitudinal study designs would be useful, even if difficult to implement.

- Data collection and evaluation methods should be attuned to the goals and attributes of exploratory search tasks. Particularly for studies related to system design, the resulting system will be more effective if it can provide seamless support through searching and into information organization, analysis, and sensemaking/ use.

A significant number of studies have investigated exploratory search, and most of those have assigned search tasks to the study subjects. The assigned search tasks vary in many ways, any of which might be influencing the outcomes of the study. If consensus can be reached concerning the definition of exploratory search and its key attributes, it is possible that researchers can develop simulated work task situations and search tasks that can be used and re-used across studies, thus building our understanding of exploratory search more efficiently.

\section{ACKNOWLEDGMENTS}

We would like to thank Elaine Toms for her helpful feedback on an earlier draft of the paper and her participation in a larger-scale project on all types of search tasks that might be assigned in experimental studies of interactive information retrieval. The findings are based on a database of searching studies and conceptual papers compiled with assistance from Dr. Toms and several graduate research assistants: Chris Doty, Jung Sun Oh, and Felix Portnoy at the University of North Carolina at Chapel Hill, and Amanda Leinberger at the University of British Columbia. We also thank the anonymous reviewers of this paper for their helpful suggestions.

\section{REFERENCES}

1. Amadieu, F., Tricot, A., \& Mariné, C. (2010). Interaction between prior knowledge and concept-map structure on hypertext comprehension, coherence of reading orders and disorientation. Interacting with Computers, 22, 8897.

2. Alhenshiri, A., Watters, C., Shepherd, M., \& Duffy, J. (2012). Building support for Web information gathering tasks. Proceedings of the 45th Hawaii International Conference on System Sciences (HICSS), 1687-1696.

3. Anderson, L.W., \& Krathwohl, D.A. (2001). A Taxonomy for Learning, Teaching and Assessing: A Revision of Bloom's Taxonomy of Educational Objectives. New York: Longman.

4. Aula, A. (2003). Query formulation in web information search. Proceedings of the IADIS International Conference WWW/Internet 2003, I, 403-410.

5. Aula, A., \& Russell, D.M. (2009). Complex and exploratory Web search. In Marchionini, G., et al. (organizers), Information Seeking Support Systems: An Invitational Workshop Sponsored by the National Science Foundation (June 26-27, 2008, Chapel Hill, $N C), \mathrm{p} 23-24$. Chapel Hill, NC: School of Information \& Library Science, University of North Carolina at Chapel Hill. http://ils.unc.edu/ISSS/ISSS_final_report.pdf.

6. Bilal, D. (2002). Children's use of the Yahooligans! Web search engine. III. Cognitive and physical behaviors on full self-generated search tasks. Journal of the American Society for Information Science and Technology, 53(13), 1170-1183.

7. Borlund, P. (2003). The IIR evaluation model: A framework for evaluation of interactive information retrieval systems. Information Research, 8(3). http://informationr.net/ir/8-3/paper152.html.

8. Borlund, P., \& Schneider, J.W. (2010). Reconsideration of the simulated work task situation: A context instrument for evaluation of information retrieval interaction. Proceedings of Information Interactions in Context (IIiX) 2010, 155-164. http://research.microsoft.com/en-us/um/people/ryenw/h cir2010/presentations.html.

9. Byström, K., \& Hansen, P. (2005). Conceptual framework for tasks in information studies. Journal of 
the American Society for Information Science \& Technology, 56(10), 1050-1061.

10. Capra, R., Marchionini, G., Oh, J. S., Stutzman, F., \& Zhang, Y. (2007). Effects of structure and interaction style on distinct search tasks. Proceedings of the 7th ACM/IEEE Joint Conference on Digital Libraries (JCDL), 442-451.

11. Dervin, B. (1992). From the mind's eye of the user: The sense-making qualitative-quantitative methodology. In J. D. Glazier \& R. R.Powell, (Eds.), Qualitative Research in Information Management. Englewood, CO: Libraries Unlimited, 6-84.

12. Diriye, A., Blandford, A., \& Tombros, A. (2010). Exploring the impact of search interface features on search tasks. Paper presented at the European Conference on Digital Libraries. Lecture Notes in Computer Science, 6273, 184-195.

13. Diriye, A., Blandford, A., \& Tombros, A. (2010). When is system support effective? Proceedings of Information Interactions in Context (IIiX), 55-64.

14. Diriye, A., Wilson, M.L., Blandford, A., \& Tombros, A. (2010). Revisiting exploratory search from the HCI perspective. HCIR 2010: Proceedings of the Fourth Workshop on Human-Computer Interaction and Information Retrieval. http://research.microsoft.com/en-us/um/people/ryenw/h cir2010/presentations.html.

15.Du, J.T., \& Evans, N. (2011). Academic users' information searching on research topics: Characteristics of research tasks and search strategies. Journal of Academic Librarianship, 37(4), 299-306.

16.Egusa, Y., Saito, H., Takaku, M., Terai, H., Miwa, M. \& Kando, N. (2010). Using a concept map to evaluate exploratory search. Proceedings of Information Interactions in Context (IIiX) 2010, 175-184.

17.Gill, T.G., \& Hicks, R.C. (2006). Task complexity and informing science: A synthesis. Informing Science, 9, $1-30$.

18. He, D., Brusilovsky, P., Ahn, J., Grady, J., Farzan, R., Peng, Y., Yang, Y., \& Rogati, M. (2008). An evaluation of adaptive filtering in the context of realistic task-based information exploration. Information Processing \& Management, 44(2), 511-533.

19. Hersh, W., Pentecost, J., \& Hickam, D. (1996). A task-oriented approach to information retrieval evaluation. Journal of the American Society for Information Science, 47(1), 50-56.

20. Ingwersen, P. \& Järvelin, K. (2005). The Turn: Integration of Information Seeking and Retrieval in Context. Dordrecth: Springer.
21. Janiszewski, C. (1998). The influence of display characteristics on visual exploratory search behaviour. Journal of Consumer Research, 25(3), 290-301.

22. Jansen, B.J., Booth, D., \& Smith, B. (2009). Using the taxonomy of cognitive learning to model online searching. Information Processing \& Management, 45(6), 643-663.

23. Kang, R., Kannampallil, T., He, J., \& Fu, W.-T. (2009). Conformity out of diversity: Dynamics of information needs and social influence of tags in exploratory information search. Foundations of Augmented Cognition. Neuroergonomics and Operational Neuroscience. Lecture Notes in Computer Science, 5638, 155-164.

24. Kim, J. (2006). Task difficulty as a predictor and indicator of web searching interaction. In $\mathrm{CHI}$ '06 Extended Abstracts on Human Factors in Computing Systems, 959-964.

25. Kim, J. (2009). Describing and predicting information-seeking behavior on the Web. Journal of the American Society for Information Science \& Technology, 60(4): 679-693.

26. Kintsch, W. (1998) Comprehension: A Paradigm for Cognition. New York: Cambridge University Press.

27. Kules, B., \& Capra, R. (2012). Influence of training and stage of search on gaze behavior in a library catalog faceted search interface. Journal of the American Society for Information Science \& Technology, 63(1), 114-138.

28. Kules, B., \& Capra, R. (2008). Creating exploratory tasks for a faceted search interface. HCIR 2008: Proceedings of the Second Workshop on Human-Computer Interaction and Information Retrieval, 18-21. http://research.microsoft.com/en-us/um/people/ryenw/h cir2008/doc/HCIR08-Proceedings.pdf.

29. Kules, B., \& Shneiderman, B. (2008). Users can change their Web search tactics: Design guidelines for categorized views. Information Processing \& Management, 44(2), 463-484.

30. Li, Y. (2009). Exploring the relationships between work task and search task in information search. Journal of the American Society for Information Science \& Technology, 60(2), 275-291.

31.Li, Y., \& Belkin, N.J. (2008). A faceted approach to conceptualizing tasks in information seeking. Information Processing \& Management, 44(6), 1822-1837.

32. MacMullin, S.E., \& Taylor, R.S. (1984). Problem dimensions and information traits. The Information Society, 3(1), 91-111.

33. Madden, A. D., Eaglestone, B., Ford, N. J., \& Whittle, M. (2007). Search engines: a first step to finding information: preliminary findings from a study of 
observed searches. Information Research, 12(2). http://informationr.net/ir/12-2/paper294.html.

34. Marchionini, G. (1989). Information-Seeking Strategies of Novices Using a Full-Text Electronic Encyclopedia. Journal of the American Society for Information Science, 40(1), 54-66.

35. Marchionini, G. (2006). Exploratory search: From finding to understanding. Communications of the ACM, 49(4), 41-46.

36. Marchionini, G., Dwiggins, S., Katz, A., \& Lin, X. (1993) Information seeking in full-text end-user-oriented search systems: The roles of domain and search expertise. Library \& Information Science Research, 15(1), 35-69.

37. Niu, Y., \& Winter, S. (2006). The effect of task type and information format on Web searching performance. ICIS Proceedings. Paper 52. http://aisel.aisnet.org/icis2006/52.

38. Poddar, A., \& Ruthven, I. (2010). The emotional impact of search tasks. Proceedings of the Third Symposium on Information Interaction in Context (IIiX), 35-44.

39. Qu, Y., \& Furnas, G.W. (2006). What do the attributes of exploratory search tell us about evaluation. Proceedings of the ACM SIGIR 2006 Workshop on Evaluating Exploratory Search Systems (EESS), 51-53.

40. Qu, Y., \& Furnas, G.W. (2008). Model-driven formative evaluation of exploratory search: A study under a sensemaking framework. Information Processing \& Management 44(2): 534-555.

41. Ramdeen, S., \& Hemminger, B. (2012). A tale of two interfaces: How facets affect the library catalog search experience. Journal of the American Society for Information Science \& Technology, 63(4), 702-715.

42. Russell, D.M., Stefik, M. J., Pirolli, P., \& Card, S. K. (1993). The cost structure of sensemaking. Proceedings of ACM INTERCHI'93, 269-276.

43. Savolainen, R. (2008). Everyday Information Practices: A Social Phenomenological Perspective. Lanham, MD: Scarecrow Press.

44. Schacter, J., Chung, G.K.W.K., \& Dorr, A. (1998). Children's Internet searching on complex problems: Performance and process analyses. Journal of the American Society for Information Science, 49(9), 840849.

45.Toms, E.G., O'Brien, H., Mackenzie, T., Jordan, C., Freund, L., Toze, S., Dawe, E., \& MacNutt, A. (2008).
Task effects on interactive search: The query factor. In Focused Access to XML Documents. Lecture Notes in Computer Science, 4862, 359-372.

46. Vakkari, P. (2010). Exploratory searching as conceptual exploration. HCIR 2010: Proceedings of the Fourth Workshop on Human-Computer Interaction and Information Retrieval. http://research.microsoft.com/en-us/um/people/ryenw/h cir2010/docs/papers/vakkari_fp10.pdf.

47. Vibert, N., Ros, C., Le Bigot, L., Ramond, M., Gatefin, J., \& Rouet, J.-F. (2009). Effects of domain knowledge on reference search with the PubMed database: An experimental study. Journal of the American Society for Information Science \& Technology, 60(7), 1423-1447.

48. White, M.D., \& Iivonen, M. (2001). Questions as a factor in Web search strategy. Information Processing \& Management, 37(5), 721-740.

49. White, R., Muresan, G., \& Marchionini, G. (2006). Proceedings of the ACM SIGIR 2006 Workshop on "Evaluating Exploratory Search Systems." http://research.microsoft.com/en-us/um/people/ryenw/ee ss/eess 2006 proceedings.pdf.

50. White, R., \& Roth, R.A. (2009). Exploratory Search: Beyond the Query-Response Paradigm. Synthesis Lectures on Information Concepts, Retrieval, and Services \#3. Morgan \& Claypool.

51. Wildemuth, B.M., de Bliek, R., Friedman, C.P. \& File, D.D. (1995). Medical students' personal knowledge, searching proficiency, and database use in problem solving. Journal of the American Society for Information Science, 46, 590-607.

52. Wolfram, D., \& Dimitroff, A. (1998). Hypertext vs. Boolean-based searching in a bibliographic database environment: A direct comparison of searcher performance. Information Processing \& Management, 34(6), 669-680.

53. Wu, W.-C., Kelly, D., Edwards, A., \& Arguello, J. (In press). Grannies, tanning beds, tattoos and NASCAR: Evaluation of search tasks with varying levels of cognitive complexity. Paper accepted for presentation at Information Interaction in Context (IIiX) 2012.

54. Xie, I., \& Cool, C. (2009). Understanding help-seeking within the context of searching digital libraries. Journal of the American Society for Information Science \& Technology, 60(3), 477-494. 